ACP for frail elderly and patients with complex chronic health problems as well as evidence for ACP interventions in this population. ACP education of Dutch elderly care physicians will be highlighted. The specific challenge for elderly care physicians in ACP for persons with decisionmaking disabilities will be discussed. Finally, the collaboration between elderly care physicians and general practitioners will be illustrated.

Content Introduction ACP in elderly care medicine - by $\mathrm{dr}$. Daisy J.A. Janssen

Specific challenges for elderly care physicians: ACP and decision-making disabilities - by prof. Cees Hertogh

Collaboration between elderly care physician and general practitioner - by general practitioner invited by dr. Annicka van der Plas

\section{OP77 THE ADVANCE PROJECT: AN AUSTRALIAN NATIONAL PROGRAM TO SUPPORT NURSES TO INITIATE ADVANCE CARE PLANNING IN GENERAL PRACTICE}

${ }^{1} \mathrm{C}$ Clayton* ${ }^{1} \mathrm{~S}$ Nagarajan, ${ }^{2} \mathrm{~V}$ Lewis, ${ }^{3} \mathrm{~K}$ Detering, ${ }^{4} \mathrm{E}$ Halcomb, ${ }^{5} \mathrm{~J}$ Tieman ${ }^{6} \mathrm{G}$ Mitchell, 7J Phillips, ${ }^{8} \mathrm{R}$ Morton, ${ }^{8} \mathrm{D}$ Costa, ${ }^{9} \mathrm{~J}$ Gavin, ${ }^{1} \mathrm{~J}$ Stokes, ${ }^{8} \mathrm{~A}$ Livingstone, ${ }^{8} \mathrm{~T}$ Shaw, ${ }^{1} \mathrm{~J}$ Rhee. ${ }^{1}$ HammondCare, Greenwich, New South Wales, Australia; ${ }^{2}$ LaTrobe University, Melbourne, Australia; ${ }^{3}$ Austin Health, Melbourne, Australia; ${ }^{4}$ University of Wollongong, Wollongong, Australia; ${ }^{5}$ Flinders University, South Australia, Australia; ${ }^{6}$ University of Queensland, Queensland, Australia; ' University of Technology, Sydney, Australia; ${ }^{8}$ University of Sydney, Sydney, Australia; ${ }^{9}$ Queensland University of Technology, Australia

\subsection{6/spcare-2019-ACPICONGRESSABS.77}

Background Primary care has been advocated as an ideal setting to initiate advance care planning (ACP). Few studies have examined the role of general practice nurses (GPNs) in promoting/initiating ACP. The Advance Project evaluated initiatives to address this gap.

Methods This Australian Government-funded program aims to increase GPNs' confidence in initiating conversations with patients/carers about ACP during routine health assessments with older and/or chronically ill patients using a structured interview. This is part of a broader program enabling GPNs to identify patients at risk of deteriorating and dying and to assess these patients' palliative/supportive care needs. Identified needs are then addressed in consultation with General Practitioners. The program includes a suite of resources and multi-component training (online, face-to-face and individual tele-mentoring). Pre/post/follow-up surveys and qualitative interviews collected GPNs' perspectives about the training/resources and barriers to implementation in clinical practice.

Results As of 31 December 2017, 823 GPNs enrolled in training and 536 completed one or more training components. 27 workshops were held across Australia, including 182 regional/ rural participants. 585 pre-training, 384 post-training, and 125 follow-up surveys were received. 20 GPNs were interviewed. There were significant improvements in GPNs' confidence, comfort, knowledge and attitudes towards initiating ACP posttraining that was sustained at follow-up. Participants were significantly more likely to have had ACP discussions with their patients at follow-up (81\%) compared to baseline (55\%, $\mathrm{p}<0.001)$.

Discussion/Conclusion GPNs can have an important role in initiating ACP. The evaluation informed refinement/expansion of the resources/training to support team-based initiation of ACP in general practice http://www.theadvanceproject.com.au

\section{OP78 REGIONAL (CENTRAL) VERSUS INSTITUTIONAL: COMPETING STRATEGIES FOR NATIONWIDE ACP IMPLEMENTATION}

1f In der Schmitten*, ${ }^{2} G$ Marckmann. 'Medical Faculty, Heinrich-Heine-University, Düsseldorf, Germany; ${ }^{2}$ Medical Faculty, LMU, Munich, Germany

\subsection{6/spcare-2019-ACPICONGRESSABS.78}

Background Implementing ACP in nursing homes is often essentially done by educating selected $\mathrm{n} / \mathrm{h}$ staff as ACP facilitators. Recent German legislation covers ACP offered to nursing home residents, and offers an alternative strategy for implementation, i.e. cooperation of participating $\mathrm{n} / \mathrm{hs}$ with a regional (central) partner that employs a team of facilitators. Which of these two strategies should be preferred?

Methods 1. Follow-up of facilitator training effectivity in Germany in 2015-2017, 2. review of the literature, 3. theoretical analysis of the competing rationales.

Results Of some 270 facilitator trainees attending our ACP courses, only few report ongoing practice as an ACP facilitator. A number of important publications describe facilitators and barriers, or essential elements, of successful ACP implementation, but few if any compare regional versus institutional implementation strategies of ACP yet. Similarly, while regional ACP coordination is described as an important precondition for sustainable ACP implementation, it requires significant resources on top of institutional implementation. A comparative analysis yields a number of strong reasons why regional may well beat institutional implementation strategies, referring to staff aptitude, team building, regional coordination, economic efficiency, and both sustainability and expandibility. Arguments that have been raised against qualifying external staff can be shown not to consider sufficiently the potential of creating regional (central) facilitator teams.

Conclusion Regional implementation of ACP, characterised by regional (central) facilitator teams cooperating with nursing homes and other institutions, has yet rarely been described, but poses a substantial potential when compared to conventional institutional implementation strategies that deserves scientific evaluation.

\section{OP79 CREATING MOMENTUM AND CONSISTENCY WITH A NATIONAL FIVE YEAR STRATEGY IN NEW ZEALAND}

L Manson*, L Price. Health Quality Safety Commission, Wellington, New Zealand

\subsection{6/spcare-2019-ACPICONGRESSABS.79}

Background The development of ACP in New Zealand was driven by the ACP Cooperative, a grass roots organisation of clinicians. The Cooperative's aim was to drive consistency and address the barriers to ACP implementation. Over time, the lack of an official mandate and funding threatened the sustainability of the work of the Cooperative.

Method In 2017 the Cooperative partnered with the Health Quality \& Safety Commission - a crown agency tasked with supporting the public health sector to improve the quality and safety of services. Together they presented a business case to the district health boards (DHBs) to agree to a national programme with a clear mandate and funding. The DHBs agreed to a five-year strategy and roadmap of national and local actions aimed at increasing ACP activity and addressing sustainability. The key strategy workstreams and their aims are: 